УДК 339.543

\title{
МИРОВОЙ ОПЫТ ТАМОЖЕННОГО ДЕЛА В КОНТЕКСТЕ ФОРМИРОВАНИЯ СТРАТЕГИИ РАЗВИТИЯ ТАМОЖЕННОЙ СЛУЖБЫ РЕСПУБЛИКИ БЕЛАРУСЬ
}

\author{
A.В. ПЕТРОВ, \\ начальник организационно-аналитического управления \\ Государственного таможенного комитета Республики Беларусь, г. Минск
}

\begin{abstract}
Аннотация
В статье анализируется проблема стратегического развития таможенной службы Республики Беларусь в аспекте адаптации к ее деятельности мирового опыта таможенных служб различных стран мира. Проведено обобщение и систематизация основных направлений развития таможенного дела с учетом складывающихся тенденций в мировой экономике, современных технологических укладов и роста криминализации на канале международной торговли.

Ключевые слова: таможенное дело, таможенная служба, наращивание потеничиала, стратегия развития, содействие торговле, борьба с правонарушениями, Всемирная таможенная организация, Всемирная торговая организация.
\end{abstract}

Abstract

In article the problem of strategic development of customs service of Republic of Belarus in aspect of adaptation to its activity of world experience of customs services of various countries of the world is analyzed. Generalization and systematization of the main directions of development of customs matter taking into account the developing tendencies in world economy, modern technological ways and growth of criminalization on the channel of international trade is carried out.

Keywords: customs matter, customs service, capacity-building, strategy development, trade facilitation, fight against offenses, World Customs Organization, World Trade Organization.

\section{ВВЕДЕНИЕ}

Современная таможенная служба Республики Беларусь находится под объективным воздействием региональных и международных вызовов и тенденций, оказывающих непосредственное влияние на ее развитие и в конечном итоге на результаты и безопасность в сфере внешнеэкономической деятельности государства.

Реализация Программ развития таможенной службы последних десятилетий позволила сформировать правовую базу таможенного дела, создать необходимые условия для полномасштабного внедрения информационно-коммуникационных технологий, гарантировать должный уровень контроля на границе, а также оптимизировать ситуацию с сокращением количества контрольных служб без потери качества осуществляемых ими контрольных операций.

Возросла пропускная способность пограничных пунктов пропуска, укреплению кадрового потенциала способствовала политика отбора, мотивации и обучения персонала.

Динамика развития внешнеэкономической деятельности, возросший уровень мобильности граждан и субъектов хозяйствования, наметившиеся тенденции снижения транзита товаров и транспортных средств через территорию Беларуси, активные инте- 
грационные процессы в рамках торгово-экономического сотрудничества обусловили необходимость проведения мероприятий, направленных на повышение транзитной и инвестиционной привлекательности государства, повышение безопасности при трансграничном перемещении товаров.

В этих условиях поэтапная модернизация и совершенствование таможенной службы видятся важными элементами обеспечения безопасности белорусского контура таможенной границы Евразийского экономического союза, развития внешнеэкономических связей республики с иными государствами и экспортно-ориентированной национальной экономики, в целом.

В этой связи, при разработке стратегии развития таможенной службы, цели и задачи формируются с учетом мирового опыта таможенного дела в направлении укрепления положительного имиджа Республики Беларусь как удобного и выгодного партнера для совместного осуществления транзитных и инвестиционных проектов.

Необходимо отметить, что процессы развития таможенной службы проходят в соответствии и строго увязаны с выполнением задач по нейтрализации внутренних и защиты от внешних угроз, определенных Концепцией национальной безопасности Республики Беларусь [1].

\section{РЕЗУЛЬТАТЫ И ИХ ОБСУЖДЕНИЕ}

\section{служб \\ Научная обоснованность применения мирового опьта развития таможенных}

Научная мысль последних лет значительно обогатила теоретическую базу таможенного дела результатами специальных и комплексных исследований. Расширилось число публикаций, ежегодно проходят научные конференции всемирного и регионального уровня.

Так, в итоговом документе VI международной научно-практической конференция «От Таможенного союза к Евразийскому экономическому союзу: современность и перспективы», состоявшейся в Минске 17 сентября 2015 года, отмечено, что упрощение и гармонизация таможенных процедур имеют особое значение в контексте интеграции ЕАЭС в международное экономическое пространство [2].

Десятилетием раньше, 10 декабря 2004 года в Варшаве, открывая международную конференцию «Таможенное право и система права» профессор Веслав Чижович, генеральный директор польской таможенной службы, констатировал: «если у нас будет очень хорошая теория, у нас будет и хорошая практика» [3].

Наиболее глубокое научное обоснование необходимости учета мирового опыта развития таможенного дела, применительно к национальной таможенной службе нашло отражение в теоретических работах российских ученых.

Доктор социологических наук, начальник научно-исследовательского центра Российской таможенной академии Кухаренко В.Б. в монографии «Управление модернизацией таможенной службы» проводит анализ вклада Всемирной таможенной организации в развитие потенциала таможенных служб различных стран мира, предлагая адаптировать огромный опыт их деятельности как социальных институтов к российским условиям [4].

Общая характеристика подходов к разработке и реализации программ реформирования и модернизации таможенных служб в зарубежных странах дана в коллективной монографии российских ученых Н.М. Блинова, В.Н. Иванова, В.Б. Кухаренко, А.Г. Пашинского «Проектирование таможенной политики» [5].

Всемирно известный шведский теоретик и практик таможенного дела, Ларс Карлссон в книге «Тhe Stairway», имеющей подзаголовок «Управление легализованной 
безопасной цепью глобальных поставок. Наращивание потенциала таможни в меняющемся мире», отмечает важность применения мирового опыта в двух аспектах [6].

Первый аспект - учет мирового опыта для собственного развития, второй аспект предоставление возможности ознакомиться с наилучшей практикой национальной таможенной службы широкому кругу заинтересованных органов государственного управления зарубежных стран.

Для примера, более ста таможенных администраций различных стран мира запросили и получили от таможенной службы Швеции информацию о концепции Stairway. Некоторые страны применили концепцию в полном объеме, другие ограничились базовыми принципами для разработки собственных моделей и концепций.

По убеждению Ларса Карлссона, генерального директора таможенной службы Швеции, избранного впоследствии руководителем директората по наращиванию потенциала Всемирной таможенной организации: «учиться у других - важнейший элемент развития».

Обобщается мировой опыт развития таможенных служб в рамках международных организаций, в частности Организация по безопасности и сотрудничеству в Европе совместно с Европейской экономической комиссией ООН издала в 2012 году справочник «Передовая практика на пунктах пересечения границы: содействие торговле и транспорту» [7].

Обе организации признавая, что содействие законной торговле и трансграничным транспортным перевозкам входит в число ключевых факторов экономического развития, издавая справочник, поставили своей целью помочь 57 государствам-участникам ОБСЕ и 56 странам-членам ЕЭК ООН в разработке пограничной и таможенной политики, соответствующей современным вызовам и угрозам, посредством распространения накопленного в этой сфере передового опыта.

Особая роль в обобщении и распространении мирового опыта таможенного дела принадлежит Всемирной таможенной организации, учрежденной в 1953 году и насчитывающей 179 стран-участниц, на долю которых приходится 98 \% мирового торгового оборота [8].

На уровне национальных нормативных актов необходимость учета международного опыта при разработке среднесрочных плановых документов нашла отражение в Основных положениях организации государственного прогнозирования в Республике Беларусь (постановление Совета Министров Республики Беларусь №1321 от 20 августа 1998 г.) [9], принятое во исполнение соответствующего закона.

Методические рекомендации по формированию государственных программ и подпрограмм, утвержденные постановлением Министерства экономики Республики Беларусь от 5 ноября 2015 г. №63 предписывают включать сопоставление текущего состояния анализируемой сферы выполнения подпрограммы с состоянием аналогичной сферы в других странах [10].

Применение мирового опыта при разработке стратегических плановых документов таможенной службы Беларуси

При подготовке программ среднесрочного развития, в частности Основных направлений развития таможенной службы Беларуси на период 2010-2015, и при их реализации выполняются мероприятия трех главных фаз организационного развития таможенной службы, рекомендованных Всемирной таможенной организацией: диагностика текущего состояния дел, стратегическое планирование и внедрение изменений в работу таможенной службы, мониторинг и оценивание достигнутых результатов.

Стратегическое планирование основывается на базовых документах, стандартах, рекомендациях и инструментах Всемирной таможенной организации. 
За прошедшие годы таможенная служба инициировала присоединение Беларуси к основополагающим конвенциям авторитетной международной организации: Гармонизированной системе описания и кодирования товаров, Найробийской конвенции по предотвращению и пресечению правонарушений в таможенной сфере, Стамбульской конвенции по временному ввозу и конвенции АТА, Киотской конвенции по упрощению и гармонизации таможенных процедур.

Выполнение обязательств по рамочным стандартам безопасности и облегчения глобальной торговли, участие в диагностической программе Всемирной таможенной организации «Колумб» послужили основанием для международного признания за таможенной службой Беларуси определенных успехов в модернизации и реформах.

Для подготовки Основных направлений развития таможенной службы Беларуси на период 2010-2015 годы рабочая группа определила ключевым элементом концептуальный документ Всемирной таможенной организации «Таможня XXI век», одобренный в 2008 году [11].

Всемирная таможенная организащия и мировой опыт таможенного дела

В первую неделю марта текущего года в Брюсселе в штаб-квартире Всемирной таможенной организации прошло заседание постоянного технического комитета. В соответствии с уставными документами организации, комитет определен ответственным рабочим органом, обеспечивающим содействие торговле и соответствие практики таможенного дела положениям международных конвенций, требованиям национальных законодательств [12].

В работе сессии приняли участие представители более 60 делегаций таможенных служб различных стран мира, экономических и таможенных союзов, международных организаций.

Секретариат комитета организовал дискуссию и обмен опытом по восьми темам, среди которых первоочередной по значимости и порядку рассмотрения определили «Будущее таможни», как ориентированную на формирование стратегического видения таможенных администраций.

Отмечена высокая практическая значимость и других тем, объединяющих вопросы таможенного дела с учетом состояния мировой торговли, развития информационных технологий и интеграционных процессов, модернизации таможенной службы: «электронная торговля», «управление цепью поставок», «сотрудничество таможни и бизнеса», «региональная интеграция», «качество информации», «оценка эффективности и результативности работы таможенной службы», «глобальная информационная сеть таможенных органов».

Тема «будущее таможни» вошла в актуальную повестку дня в соответствии с решениями, принятыми на предыдущих заседаниях Постоянного технического комитета. Дискуссия развернулась вокруг подготовленного секретариатом ВТамО проекта одноименного документа, оценивающего и расширяющего с учетом новых реалий документ «Таможня в 21 веке».

Для выработки концептуальных подходов к формированию стратегии развития таможенной службы Беларуси на период 2016-2025, целесообразно прокомментировать отдельные положения документа и мнения экспертов, высказанные на состоявшемся заседании Постоянного технического комитета.

В оценке современных условий работы отмечается, что Соглашение Всемирной торговой организации о содействии международной торговле, заключенное в декабре 2013 года, переместило таможенную службу вместе с другими контрольными органами, работающими на границе, в фокус общественного внимания и возросшего ожидания в отношении улучшений на границе. Этим соглашением дан импульс инвестици- 
онным проектам, содействующим торговле и значительным улучшениям в процедурах трансграничного перемещения товаров.

Положения Соглашения в аспекте применения для определения направлений развития таможенной службы Беларуси проанализированы автором в докладе, подготовленном совместно с О.И. Яхновичем для научной конференции «Управление в области таможенного дела», состоявшейся в Минске 20 марта 2014 г. [13].

Существенный прорыв сделан в рамках Всемирной торговой организации в переговорах по расширению применения Соглашения по информационным технологиям. Во всем мире электронная трансграничная торговля показывает удивительные темпы роста благодаря сочетанию таких факторов как постоянный прогресс интернет технологий и экономический подъем в странах с развивающейся экономикой.

В этой связи стоит отметить, что по данным исследований агентства Forrester, опубликованным в феврале текущего года, ежегодный объем электронных продаж составляет более одного триллиона долларов с прогнозируемым удвоением в ближайшие четыре года.

Относительно роли и места таможенной службы авторы современного исследования отмечают, что даже после семи лет, прошедших с момента принятия стратегического документа «Таможня в 21-м веке», данное в нем определение таможни охватывает большинство, если не все функции таможенной службы.

По-прежнему, «таможенная служба призвана контролировать движение товара и посредством этого защищать интересы государства и гарантировать сбор поступлений в бюджет.

Основные цели деятельности таможни заключаются в обеспечении соответствия трансграничного перемещения товаров государственной политике и применяемому законодательству, обеспечении должного уровня борьбы с контрабандой, безопасности границ при гарантированном создании необходимых условий для легитимной торговли».

Тем не менее, безусловно, повлияют на роль таможенной службы в будущем организационные изменения, происходящие в различных направлениях.

Один из примеров - проявившаяся тенденция увеличения числа таможенных служб, участвующих в контроле трансграничного перемещения людей. Страны применяют различные системы контроля на границе. В ряде случаев значительное число контролирующих органов работают рядом с таможней, обеспечивая эффективный менеджмент на границе.

Таможни играют заметную и ответственную роль в координации работы контролирующих органов на границе и зачастую проводят предварительные проверки по поручению других контролирующих служб.

В отдельных странах таможня и иммиграционная служба работают в тесном взаимодействии или объединены в одну службу, контролирующую перемещение пассажиров, с целью выявления контрабанды наркотиков, террористической или иной незаконной деятельности. В этом случае, предварительная информация о пассажире и ведение базы данных о пассажирах становятся незаменимыми инструментами менеджмента на границе.

За последние несколько лет заметно продвинулись проекты, реализуемые с участием таможенных служб: «координированное управление на границе», «одно окно» и «уполномоченный экономический оператор». Кардинально возросло количество соглашений о взаимном признании статуса «уполномоченный экономический оператор» и, соответственно, наращиваются объемы сделок между участниками международной торговли, имеющими такой статус.

Несмотря на безусловные преимущества и широкие возможности, появившиеся вместе с впечатляющим ростом интернет продаж, электронная торговля также выявила определенные угрозы для таможенной службы в достижении основных целей. Ощуща- 
ется, что процедуры в местах контроля перемещения товаров в почтовых отправлениях еще не полностью адаптированы к скорости и объемам почтового оборота.

Проведенная Всемирной таможенной организацией операция Skynet подтвердила, что почтовые поставки и экспресс поставки используются для контрабандных целей, в частности, незаконного ввоза наркотиков и химических прекурсоров. Всемирная таможенная организация в прошедшем году сделала акцент на необходимости предварительной информации и использовании автоматизированной системы анализа рисков при контроле товаров почтового оборота.

Подтверждают тенденцию роста почтовых и экспресс поставок данные, приведенные в периодическом издании международного бюро контейнеров [14].

На диаграмме представлены десять крупнейших логистических операторов, обрабатывающих половину всемирного товарного оборота, при этом на долю лишь трех операторов почтовых и экспресс поставок: DHL, UPS, FEDEX приходится четверть всего оборота.

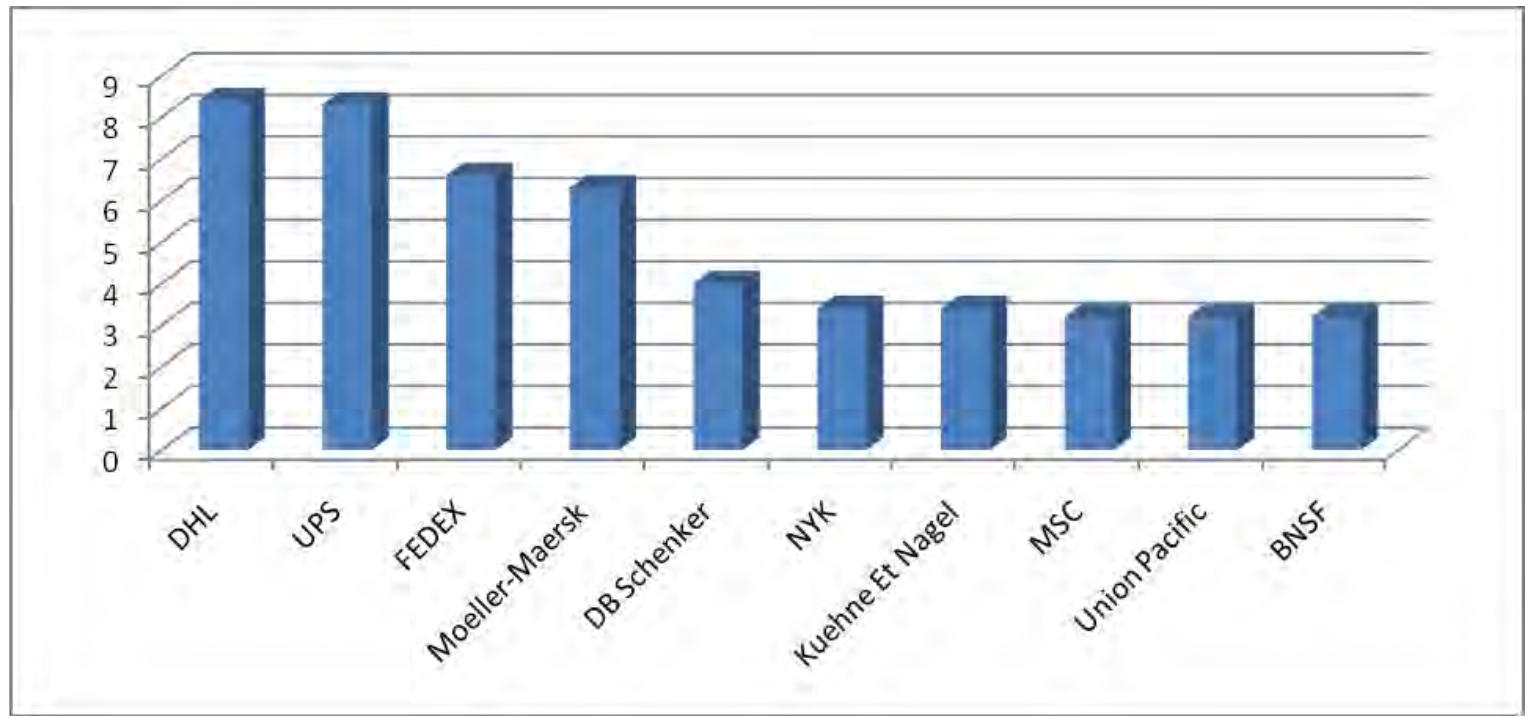

Рисунок 1 - Крупнейшие логистические операторы

Впечатляющие успехи технологически оснащенного малого бизнеса, отмеченные во всем мире в прошедшие годы, существенно повлияли на торговую среду и внесли вклад в конкурентоспособность национальных экономик. Благодаря интернету и новым технологиям, малый бизнес, как никогда до этого, имеет возможность шагнуть дальше национального потребительского рынка и предложить товары и услуги в глобальном масштабе.

Желая поддержать бизнес, в части подключения к глобальной цепочке создания ценностей, таможенные администрации пересматривают процедуры по переработке вне территории и на территории страны, и определяются в том, как оказать специальную поддержку микро, малым и средним предприятиям в повышении их активности на международном рынке.

\section{Экспертная оиенка мировых тенденций}

В ходе заседания Постоянного технического комитета о «будущем таможни» высказались эксперты, представлявшие таможенные службы и деловое сообщество. Открыл дискуссию советник канадского агентства служб на границе, отметив возможность заглянуть на тридцать лет вперед без боязни «воспарить к облакам».

По его мнению, определенно можно назвать характеристики деловой среды, которые придется учитывать таможне при решении повседневных задач: изменение культуры общества в широком смысле, партнерские отношения с бизнесом, технологическая 
модернизация, возрастание объема международной торговли, наполнение государственного бюджета. И, конечно же, этот перечень не исчерпывающий.

В соответствии со сложившимся инновационным ритмом, каждые три года таможенная служба должна осуществлять модернизацию, определяя новые показатели и достигая их, чему послужит стратегическое видение и планирование реформ.

Определяющую роль в развитии таможенного дела сыграют новые технологии, новые математические модели, академический научный подход в определении проблем и их решении.

Компьютеры на молекулярной и оптической основе позволят настолько эффективно применять электронные технологии, что понятие «электронная таможня» трансформируется в «электронную Всемирную таможенную организацию», привычными станут понятия «виртуальная таможня» и «виртуальная граница».

Неожиданно, но вполне объяснимо с учетом опыта белорусской таможенной службы в координации усилий ведомств в налаживании информационного обмена, прозвучал призыв представителя таможни Японии не идеализировать роль информационных технологий в таможенном деле, как таковых.

Предлагается в большей мере видеть цель и последствия применения информационных технологий для совместной работы таможни с другими правоохранительными службами на границе, а также с бизнесом.

Консультант по вопросам бизнеса из Нидерландов, отметил важную тенденцию последних 10-15 лет: таможенной службе необходимо и приходится успевать за технологическими изменениями, происходящими в деловой среде и торговой практике, дабы не сдерживать международные товарные потоки.

В аргументацию тезиса приведен простой и запоминающийся пример: разница между современными технологиями бизнеса и технологиями пятнадцатилетней давности такая же, как между телефоном и смартфоном.

Докладчиком отмечена перспективность использования информационных технологий для реализации проекта «единое окно».

\section{ВЫВОДЫ}

На основании консолидированного экспертного мнения, сформированного на площадках и в рабочих органах специализированных международных организаций, практики работы таможенных служб различных стран мира, результатов научных исследований в сфере международной торговли и таможенного дела представляется возможным сформировать ряд ключевых факторов, влияющих на перспективу развития таможенной службы:

- имплементация положений пересмотренной Киотской конвенции об упрощении и гармонизации таможенных процедур в национальные законодательства и практику таможенного дела с учетом современных информационных и управленческих технологий;

- сотрудничество таможни с бизнесом, сфокусированное на создании благоприятных условий для международной торговли;

- применение информационных технологий, соответствующих современному технологическому укладу и обеспечивающих работу таможни в условиях «цифровой экономики»;

- понимание необходимости межведомственного сотрудничества внутри государства и на межгосударственном уровне, в частности реализация проекта «одно окно»;

- интеграция систем анализа рисков, как ответ на вызов в виде роста трансграничной торговли;

- сотрудничество на региональном уровне, включая вопросы взаимного признания Уполномоченных экономических операторов и налаживания информационного обмена;

- интегрированный менеджмент на границе в условиях значительного роста миграционных и товарных потоков; 
- создание собственных систем получения новых знаний.

Мировое таможенное сообщество едино во мнении, что все действия по развитию таможенной службы должны носить эволюционный, а не революционный характер, поскольку таможня это составляющая часть экономической системы государства.

Завершая статью, подчеркивая важность прогнозной оценки, основанной на мировом опыте таможенного дела, для построения концептуальной модели таможенной службы ближайших десяти лет, процитирую российского ученого с мировым именем в сфере научного прогноза.

Академик Российской академии общественных наук Игорь Васильевич БестужевЛада в монографии «Социальное прогнозирование» пишет: «решение о выборе, постановке той или иной цели может быть произвольным, спонтанным, импульсивным, волюнтаристским, субъективистским, хотя может и должно базироваться на научной информации аналитического, диагностического и прогностического характера - отсюда вытекает необходимость целевого прогноза» [15].

\section{ЛИТЕРАТУРА}

1. Национальная безопасность Республики Беларусь / С. В. Зась [и др.]; под ред. М. В. Мясниковича и Л. С. Мальцева. - Минск: Беларус. навука, 2011. - 557 с.: ил.

2. Итоговый документ VI международной научно-практической конференции «От Таможенного союза к Евразийскому экономическому союзу: современность и перспективы» [Электронный ресурс]. - Минск, 2015. - Режим доступа: http://www.gtk.gov.by/ru/press-center/news/itogovyi...6533.html - Дата доступа: 17.12.2015.

3. Вступительное слово профессора В. Чижовича на конференции «Таможенное право в системе права»// Материалы международной конференции; ред. проф. Веслав Чижович, проф. Януш Мерски. - Варшава, 2005.

4. Кухаренко, В.Б. Модернизация таможенной службы. Монография / В.Б. Кухаренко. - М.: ИЦ «Классика», 2000. - 352 с.

5. Блинов, Н.М. Проектирование таможенной политики / Н.М. Блинов, В.Н. Иванов, В.Б. Кухаренко, А.Г. Пашинский. - М.: Книга и бизнес, 2001. - 328 с.

6. Карлссон, Ларс «The Stairway» Управление легализованной безопасной цепью глобальных поставок. Наращивание потенциала таможни в меняющемся мире. / Ларс Карлссон - Таможенная служба Швеции, 2005. - 288 с.

7. Передовая практика на пунктах пересечения границы: содействие торговле и транспорту. Справочник ОБСЕ - ЕЭК ООН / Организация по безопасности и сотрудничеству в Европе совместно с Европейской экономической комиссией Организации Объединенных Наций, 2012. - 306 с.

8. Всемирная таможенная организация. Историческая справка. [Электронный pecypc]. - Режим доступа: http://www.wcoomd.org/en/about-us/what-is-the-wco/au_ history.aspx. - Дата доступа: 17.12.2015.

9. Основные положения организации государственного прогнозирования в Республике Беларусь [Электронный ресурс]: пост. Совета Министров Респ. Беларусь, 20 августа 1998 г., №1321 // Эталон в мире права / Нац. центр правовой информ. Респ. Беларусь. - Минск, 2015.

10. Методические рекомендации по формированию государственных программ и подпрограмм [Электронный ресурс]: пост. Мин. эконом. Респ. Беларусь, 5 ноября 2015 г., №63 // Эталон в мире права / Нац. центр правовой информ. Респ. Беларусь. Минск, 2015.

11. Всемирная таможенная организация. Роль таможенной службы в 21 веке. [Электронный ресурс] - Режим доступа: http:/www.wcoomd.org/Public/Global/PDF/ About\%20us/legal\%20instruments/Resolution/Role..._June\%202008._.ashx?db=web. - Дата доступа: 17.12.2015. 
12. Всемирная таможенная организация. Постоянный технический комитет. [Электронный ресурс]. - Режим доступа: http://www.wcoomd.org/en/topics/facilitation/ resources/ /media/OA7163DA1BB548969F2BEC3E3E3B12FO.ashx. - Дата доступа: 17.12.2015.

13. Петров, А.В. Инициативы Всемирной таможенной организации в аспекте инновационного подхода в управлении таможенной службой Беларуси. / А.В.Петров, О.И.Яхнович // Управление в области таможенного дела: сб. материалов I Междунар. научн. конф. - Минск, 20 марта 2014г. - С. 115-121.

14. Logistics Champions and Others / Containers // International periodical magazine / Bureau international des containers. - 2013. - №3. - С. 17-18.

15. Бестужев-Лада, И.В. Социальное прогнозирование / И.В. Бестужев-Лада, Г.А. Наместникова. [Электронный ресурс]. - Режим доступа: http://litresp.ru/chitat/ru/\%DO\%91/bestuzhev-lada-i/socialjnoe-prognozirovanie/48/ - Дата доступа: 17.12.2015.

Статья поступила в редакичию 18 декабря 2015 года. 